\title{
Preparedness of pre-intern medical graduates of three universities in Sri Lanka to diagnose and manage anaphylaxis
}

Chandrani Nirmala Wijekoon ${ }^{1 *}$, Indika Wettasinghe ${ }^{1}$, Dinithi Fernando ${ }^{2}$, Arosha Sampath Dissanayake ${ }^{3}$, Malinda Gunawardana², Gayani Minuwanpitiya ${ }^{3}$ and Palinda Thenuwara ${ }^{1}$

\begin{abstract}
Background: Early recognition and the optimal management of anaphylaxis saves lives but studies from different countries have demonstrated gaps in knowledge and practices between healthcare workers. There is a paucity of such data from Sri Lanka. We assessed knowledge, perception and self-confidence in the diagnosis and management of anaphylaxis amongst pre-intern medical graduates who would soon become first-contact doctors attending emergencies.

Methods: This cross-sectional study included pre-interns who graduated with Bachelor of Medicine, Bachelor of Surgery (MBBS) degrees in 2019 from three Sri Lankan universities with differing undergraduate curricula. Using consecutive sampling data were collected within four months of the final-MBBS examinations with a self-administered questionnaire and the answers on case diagnosis and management were used as the basis of outcome scores.

Results: 385 participants responded (response rate: 91.5\%). 16.4\% correctly identified all anaphylaxis triggers. Only 7.3\% correctly diagnosed all ten case scenarios and 34.5\% all seven cases of anaphylaxis. 98.2 and 97.9\% correctly identified 1:1000 adrenaline as the first-line treatment and the intramuscular route. $9.9 \%$ would preferentially but incorrectly use the intravenous route if access was available. Only 79.2 and 55.6\% knew the correct adult and paediatric doses of adrenaline and $50 \%$ agreed that follow-up care was needed. The mean scores for case diagnosis and management of anaphylaxis were 7.7/ $10 \pm 1.4$ and 16.9/20 \pm 1.9 , respectively. Multiple linear regression indicated that the final MBBS results classification (class of degree or no class indicated) was a positive predictor of case diagnosis score [class vs no class: $\mathrm{B}=0.662(95 \% \mathrm{Cl} 0.347-$ $0.978), p<0.001]$ and being a graduate of University $2[B=1.568(95 \% \mathrm{Cl} 1.182-1.953), p<0.001]$ and passing with a class at final MBBS $[B=0.716$ (95\% Cl 0.319-1.113), $p<0.001$ ] were positive predictors of management score. Self confidence in diagnosing and managing anaphylaxis were rated as 79.7 and $62.1 \%$ and there was a positive correlation between knowledge and perception scores and self-confidence (case-diagnosis: $r_{\mathrm{pb}}=0.111, p=0.03$; management: $r_{\mathrm{pb}}=0.164, p=$ 0.001).

(Continued on next page)
\end{abstract}

\footnotetext{
*Correspondence: nirmalawijekoon@sjp.ac.lk

${ }^{1}$ Department of Pharmacology, Faculty of Medical Sciences, University of Sri Jayewardenepura, Gangodawila, Nugegoda, Sri Lanka

Full list of author information is available at the end of the article
}

(C) The Author(s). 2021 Open Access This article is licensed under a Creative Commons Attribution 4.0 International License, which permits use, sharing, adaptation, distribution and reproduction in any medium or format, as long as you give appropriate credit to the original author(s) and the source, provide a link to the Creative Commons licence, and indicate if changes were made. The images or other third party material in this article are included in the article's Creative Commons licence, unless indicated otherwise in a credit line to the material. If material is not included in the article's Creative Commons licence and your intended use is not permitted by statutory regulation or exceeds the permitted use, you will need to obtain permission directly from the copyright holder. To view a copy of this licence, visit http://creativecommons.org/licenses/by/4.0/ The Creative Commons Public Domain Dedication waiver (http://creativecommons.org/publicdomain/zero/1.0/) applies to the data made available in this article, unless otherwise stated in a credit line to the data. 
(Continued from previous page)

Conclusions: Knowledge, perception and self confidence in the diagnosis and management of anaphylaxis was sub optimal amongst pre-interns and we identified areas that need improvement. A higher MBBS qualification classification was a predictor for correct diagnosis and management and confidence in diagnosis and management positively correlated with knowledge and perception scores. Further and enhanced educational and training strategies are needed for this life threatening emergency condition.

Keywords: Anaphylaxis, Diagnosis, Management, Knowledge, Self-confidence, Pre-intern medical graduates, Sri Lanka

\section{Background}

Anaphylaxis is a life-threatening, acute hypersensitivity reaction affecting multiple organ systems including the cardiovascular, respiratory, gastrointestinal systems and skin [1-5]. It occurs within minutes or hours following exposure to an allergen. It progresses rapidly and usually reaches its peak within 5-30 min. Protracted anaphylaxis, a rare manifestation, can last several days. The most frequent aetiological factors include food items, medications and insect stings $[1,4]$. However, anaphylaxis can occur following exposure to any substance with the ability to set off systemic degranulation of mast cells and basophils and can thus occur in any setting. Prompt diagnosis and optimal management is of utmost importance in reducing morbidity and mortality and adequate knowledge and skills in diagnosing and managing anaphylaxis is thus a pre-requisite.

As the incidence of allergies is increasing, anaphylaxis is encountered more frequently. An increasing trend has been reported in children and young adults [6-8]. The incidence shows a wide variation, with systematic reviews reporting a range from 1 to 761 per 100,000 person-years in children [8] and 1.5 to 7.9 in the general population [9]. There are no studies on the incidence or prevalence in Sri Lanka.

In the emergency setting the diagnosis of anaphylaxis is based on the clinical presentation and the key is pattern recognition. The onset is acute, usually within $2 \mathrm{~h}$ of allergen exposure, with rapid progression. Typically, clinical features involve two or more systems including skin and mucous membranes, cardiovascular, respiratory and gastrointestinal systems [1, 2, 4]. The involvement of more than one system is characteristic and helps to differentiate life-threatening anaphylaxis from simple allergy, which lies at the opposite end of the spectrum of hypersensitivity reactions. However, in the context of hypotension after exposure to a known allergen in a particular patient, anaphylaxis is diagnosed with systemic involvement of a single body system [1].

There are set criteria for diagnosing anaphylaxis across different contexts. These are described in guidelines developed by the World Allergy Organization (WAO), the American Academy of Allergy, Asthma and Immunology (AAAAI), the American College of Allergy, Asthma and
Immunology (ACAAI), and the European Academy of Allergy and Clinical Immunology (EAACI) [1, 2, 4, 5]. These criteria are highly sensitive (96.7\%) and specific (82.4\%) [4].

The first-line treatment in anaphylaxis is adrenaline, a life saving drug. Adrenaline is administered intramuscularly to the mid-anterolateral thigh, in a dose of $0.01 \mathrm{mg} /$ $\mathrm{kg}$ of a $1: 1000(1 \mathrm{mg} / \mathrm{mL})$, up to a maximum of $0.5 \mathrm{mg}$ in adults and $0.3 \mathrm{mg}$ in children as soon as anaphylaxis is diagnosed or strongly suspected [1-5]. Glucocorticoids, antihistamines and nebulisation with beta- 2 adrenergic agonists comprise second-line therapy [1] and have a supportive role. The immediate life-threatening manifestations of anaphylaxis, such as hypotension and angioedema, are relieved only by adrenaline.

Although mortality and morbidity due to anaphylaxis can be minimized with prompt diagnosis and appropriate management, studies from developed and developing countries have shown that its management is suboptimal [10, 11]. In Sri Lanka, clinical experience from deaths due to anaphylaxis suggests that it continues to be managed sub-optimally.

Studies from different countries indicate that there are gaps in knowledge, attitudes and practices about anaphylaxis amongst health care workers [12-18]. The only previous study from Sri Lanka found that there were multiple deficiencies in knowledge and practice among first contact doctors in one district [19].

The aim of our study was to assess knowledge, perception and self-confidence around the diagnosis and management of anaphylaxis in recently qualified medical graduates awaiting their internship appointments. They would soon become the first contact doctors primarily responsible for dealing with anaphylaxis in hospital settings. The study was expected to identify potential deficiencies in their diagnosis and management abilities and to facilitate improvements in undergraduate and professional development programmes.

Most previous studies have included practicing doctors but none have evaluated pre-interns [12-19]. A study from India included medical and nursing students and interns [14] and most have concentrated on the emergency management of anaphylaxis [12-14, 16, 17]. Apart from a study from Sri Lanka none have evaluated 
knowledge around triggers [12-19]. Diagnostic skills were assessed using case scenarios in two studies [18, 19] but long term management is a further area which has not been evaluated in most studies. No previous study has assessed levels of self-confidence in the diagnosis and management of anaphylaxis. Our study, on pre-interns, included a combination of salient factors including potential anaphylaxis triggers, knowledge of diagnosis, awareness of acute and long-term management requirements and levels of self-confidence in diagnosing and management.

\section{Methods}

The study was conducted adhering to relevant guidelines and regulations.

\section{Study setting and participants}

This was a cross-sectional study which included preinterns who graduated MBBS in 2019 from three selected Sri Lankan universities with different curricula. The four pre-interns who collected data were excluded. In Sri Lanka there are eleven state universities that offer undergraduate medical education and these three were selected purposively, based on feasibility. Their graduates represent a third of all annual medical graduates and the three chief types of medical curricula used in Sri Lankan medical schools. Two of the study universities, Universities 1 and 2, are located in the Western Province and University 3 in the Southern Province.

University 1 has a system-based curriculum with horizontal and vertical integration spanning three phases: preclinical, paraclinical and clinical. Although their teaching is system-based, the assessments are subjectbased. In University 2, the curriculum is system-based and organized into five streams: Basic Sciences, Applied Sciences, Community, Behavioural Sciences and Clinical Sciences. The Basic Sciences stream is in the pre-clinical phase and the Applied Sciences stream is in the paraclinical phase. In the Applied Sciences Stream the assessments are system-based whereas in the other streams they are subject-based. The entire curriculum of University 3 is subject-based. The teaching and assessments are both conducted in a subject-based manner in the preclinical, paraclinical and the clinical phases. In all three universities clinical training starts in the third year and the students receive full time clinical training in the final year. The final MBBS assessments of the three universities, comprising theory and clinical examinations, are comparable. The Multiple Choice Questionnaire (MCQ) component of the final year subjects is held as a common examination for all the faculties of Medicine in the country. In the three universities, the paraclinical phase has dedicated teaching slots on anaphylaxis. During the clinical training there is no dedicated time allocated to teaching anaphylaxis, and the learning is opportunistic depending on the availability of such patients. Paraclinical and clinical assessments include questions on anaphylaxis.

\section{Sampling}

Consecutive sampling was done using the final MBBS examination result sheets of the three medical faculties as the sampling frame. All who successfully graduated in 2019 were invited to join the study. The intended sample size was 421 (University 1, 146; University 2, 184; University 3,91$)$.

\section{Study instruments}

The study instrument was a questionnaire of two parts (Additional file 1). Part A was self-administered and obtained demographic and background details such as age, gender, personal and family history of allergy and anaphylaxis to assess perceptions and self-confidence in diagnosis and management. The questionnaire comprised case scenarios, true/false questions, single answer MCQs and open-ended questions. Of the ten casescenarios in Part A (section 2.1-2.10), the most likely diagnosis was anaphylaxis in seven, allergy in two and "other" in one. The correct responses to the questions were based on the 2011 World Allergy Organization Guidelines for the Assessment and Management of Anaphylaxis [1]. Part B of the questionnaire recorded the categorization of the final MBBS results (class of degree) from the official result sheets. Face validity of the selfadministered questionnaire was assessed by two experts including a clinician.

\section{Data collection procedure}

The contact details of all those who were in the sampling frame were recorded and they were contacted via email or telephone. When a potential participant agreed to receive the electronic versions of the study documents (on Google forms), an email with a unique study number and a link to the Google form was sent to them. The form consisted of the participant information sheet, the consent form and Part A. Clarifications related to study participation were provided when requested. The data collected from Part A was linked with degree classification data from Part B. The research team did not have access to raw marks for any of the respondents. The degree classifications were categorized into four: first-class, second class upper division, second class lower division and pass. Data from the forms were incorporated into a password protected SPSS spreadsheet and data cleaning performed by the principal investigator. Data collection was done in 2019, from University 1 in April; 2 in August and 3 in September. No incentives were provided for participation. 


\section{Statistical analyses}

Data were analysed using SPSS 21. Percentages and means were used to describe the characteristics of the study population and performance with regard to knowledge, perception and self-confidence. In the selfadministered questionnaire, the 10 case scenarios for the diagnosis of anaphylaxis and the 20 questions related to the management, were equally weighted. Every correct answer scored one point and incomplete or incorrect responses scored zero. The Chi squared test, independent sample t-test and one-way ANOVA were used to assess the statistical significance of associations. The Tukey test was performed post-hoc for ANOVA. Multiple linear regression analysis was used to describe the predictors of scores for diagnosis and management. The correlation between the self-confidence and scores for knowledge and perception was assessed with point biserial correlation and $p$ values less than 0.05 were considered to be statistically significant.

\section{Ethical considerations}

The Ethics Review Committee of the Faculty of Medical Sciences, University of Sri Jayewardenepura, Sri Lanka approved the study [Ref. No.03/19]. Study participants provided informed consent prior to recruitment and their contact details, required for communication purposes, were collected and stored separately and not included in the SPSS data sheet.

\section{Results}

Of 421 eligible subjects, 385 responded, providing a response rate of $91.5 \%$ (University $1, n=135$, response rate 92.5\%; University $2, n=170$, response rate $92.4 \%$; University $3, n=80$, response rate $87.9 \%$ ). The mean age was $27.3 \pm 1$ years (range23-29 years) and $64.2 \%$ were women. The mean duration from the final MBBS examination to the time of data collection was $2.7 \pm 1$ months. The response rate and the characteristics of the study participants from the three universities are detailed in Table 1.

\section{Knowledge regarding triggers of anaphylaxis}

Only $16.4 \%$ of the respondents correctly identified all the 33 triggers provided. Even though anaphylaxis triggered by inhalant allergens is rare, $80.8 \%$ selected each of pollen and animal fur as triggers. More than $80 \%$ identified common triggers such as shellfish, fish, beef, pork, cow's milk, egg, pineapple, tomato, peanuts, tree nuts, penicillins, cephalosporins, quinolones, NSAIDs, blood and blood products, contrast media, vaccines, anti-venom serum, anti-rabies serum, latex and cosmetic products. However, locally relevant triggers such as chickpeas (Kadala), green gram (Mung), green leaves like spinach and Sarana (Boerhavia diffusa), coconut, banana and rice were correctly identified by $\leq 40 \%$. Wheat, sesame and soy were identified as triggers by $55.3,56.4$ and $63.1 \%$. Based on university, there were differences observed in knowledge regarding certain triggers (Additional File 2 - Supplementary Table 1).

\section{Knowledge and perception regarding diagnosis of anaphylaxis}

Only 7.3\% correctly diagnosed all 10 case scenarios provided. Out of the 10 cases, seven were anaphylaxis and $34.5 \%$ diagnosed all correctly. Universities 2 and 3 did better than University 1 with regard to the diagnosis in cases of anaphylaxis $(p=0.03)$. (Additional File 2 - Supplementary Table 2). Overall, the worst performance was with regard to Case 9 where the correct diagnosis was allergy [case scenario: A patient with a history of allergy to ibuprofen develops acute onset wheezing with no other symptoms or signs after taking diclofenac]. Only

Table 1 Response rate and the characteristics of the study participants ( $n=385$ )

\begin{tabular}{|c|c|c|c|c|}
\hline & $\begin{array}{l}\text { Overall } \\
(N=385)\end{array}$ & $\begin{array}{l}\text { University } 1 \\
(N=135)\end{array}$ & $\begin{array}{l}\text { University } 2 \\
(N=170)\end{array}$ & $\begin{array}{l}\text { University } 3 \\
(N=80)\end{array}$ \\
\hline Response rate & $91.5 \%(385 / 421)$ & $\begin{array}{l}92.5 \% \\
(135 / 146)\end{array}$ & $92.4 \%(170 / 184)$ & $87.9 \%(80 / 91)$ \\
\hline Mean duration from final MBBS to data collection (months) & $2.7 \pm 1$ & $4 \pm 0$ & $2 \pm 0$ & $2 \pm 0$ \\
\hline Mean age (years) & $27.3 \pm 1$ & $27.0 \pm 1$ & $27.3 \pm 1$ & $27.5 \pm 1$ \\
\hline Women (\%) & 64.2 & 60.7 & 60.6 & 77.5 \\
\hline \multicolumn{5}{|l|}{ Results category (\%) } \\
\hline First-class & 4.9 & 6.7 & 5.3 & 1.3 \\
\hline Second-class upper division & 26.0 & 32.6 & 30.0 & 6.3 \\
\hline Second-class lower division & 40.5 & 37.0 & 44.1 & 38.8 \\
\hline Pass & 28.6 & 23.7 & 20.6 & 53.8 \\
\hline Personal history of allergy present (\%) & 31.7 & 23.7 & 40.6 & 26.3 \\
\hline Family history of allergy present (\%) & 35.3 & 27.4 & 38.2 & 42.5 \\
\hline
\end{tabular}


$36.9 \%$ diagnosed it correctly as allergy and 49.1\% thought it was anaphylaxis. The second worst performance was with regard to Case 4 where the correct diagnosis was anaphylaxis [case scenario: A patient with history of allergy to prawns, develops vomiting, diarrhoea and hypotension an hour after eating "Sarana" (a green leafy vegetable)]. 57.9\% diagnosed this as anaphylaxis and $34.8 \%$ thought the diagnosis was something else. (Fig. 1). 10.7 and 6.3\% were unaware that anaphylaxis can occur without hypotension and skin manifestations and 16\% did not know that criteria for diagnosing anaphylaxis existed. (Additional File 2 - Supplementary Table 2).

\section{Submitted separately}

The overall mean score for case diagnosis was $7.7 \pm 1.4$ out of 10. The Shapiro-Wilks test (all $p$ values $<0.05$ ) and visual inspection of the histograms, normal Q-Q plots and box plots indicated that the case diagnosis score showed linearity in different categories related to gender, university, final MBBS results, and personal and family history of allergy. There was a significant difference in the mean score for case diagnosis based on the final MBBS results category $(p<0.001)$ (Table 2). Posthoc analysis with the Tukey test showed that there was a significant difference between first class vs second lower, first class vs pass without a class, second upper vs pass without a class and second lower vs pass without a class (all $\mathrm{p}$ values $<0.05$ ). Multiple linear regression analysis showed that results indicating high performance at the final MBBS positively predicted the case diagnosis score [first class vs no first class: $\mathrm{B}=0.887$ (95\% CI $0.261-$ 1.514), $p=0.006$; class vs no class: $\mathrm{B}=0.662(95 \% \mathrm{CI}$ 0.347-0.978), $\mathrm{p}<0.001$ ] (Table 3).

\section{Knowledge and perception regarding management of anaphylaxis}

$98.2 \%$ of the respondents correctly identified 1:1000 adrenaline as the first-line treatment and $97.9 \%$ selected the intramuscular route. However, $13 \%$ incorrectly thought that salbutamol nebulisation was the first-line treatment if wheezing was the prominent symptom, whereas $9.9 \%$ were of the impression that if there is access, adrenaline must be administered intravenously. Only 79.2 and $55.6 \%$ stated the correct adult and paediatric doses of 1:1000 adrenaline. Ischaemic heart disease, a history of hypertension, tachycardia and pregnancy were considered contraindications for adrenaline by 7.8 , 4.7, 6.5 and 1.9\%, respectively. More than $20 \%$ had deficiencies related to knowledge about site of administration of intramuscular adrenaline, the positioning of the patient and intravenous fluid management. 26.8\% thought that a person with a past history of anaphylaxis should never be future exposed to any substance identified as allergens in humans. 50\% did not know that follow up care was needed those who have had anaphylaxis but $96 \%$ were aware of adrenaline self-use auto-injectors. University 2 responders did better regarding questions on the emergency management. (Additional File 2 Supplementary Table 2).

The mean score for the management of anaphylaxis was $16.9 \pm 1.9$ out of 20 . The Shapiro-Wilks test (all $p$ values $<0.05$ ), visual inspection of the histograms, normal Q-Q plots and box plots indicated that the management score showed linearity in different categories related to gender, university, final MBBS categorisation, personal and family history of allergy. There was a significant difference in the mean score for management based on the final MBBS results category $(p<0.001)$, the university $(\mathrm{p}<0.001)$ and the presence of a personal

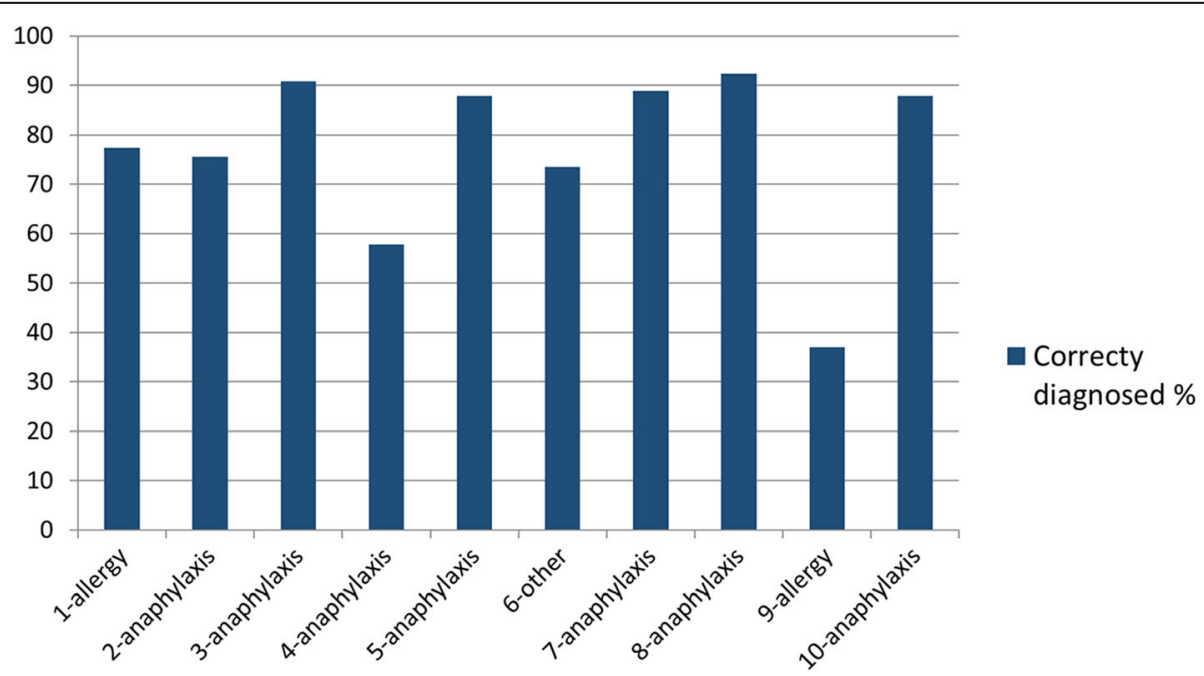

Fig. 1 Diagnosis of case scenarios 
Table 2 Mean score for case-diagnosis and management of anaphylaxis ( $N=385)$

\begin{tabular}{|c|c|c|c|c|c|c|}
\hline & & & $\begin{array}{l}\text { Mean score for } \\
\text { case-diagnosis (out of 10) }\end{array}$ & $P$ value & Mean score for management (out of 20) & $P$ value \\
\hline \multicolumn{3}{|l|}{ Overall } & $7.72 \pm 1.4$ & & $16.98 \pm 1.9$ & \\
\hline \multirow[t]{3}{*}{ University: } & : 1 & & $7.59 \pm 1.5$ & $0.350^{\#}$ & $16.36 \pm 1.7$ & $<0.001^{\#+}$ \\
\hline & 2 & & $7.78 \pm 1.3$ & & $17.96 \pm 1.5$ & \\
\hline & 3 & & $7.83 \pm 1.2$ & & $15.96 \pm 2.1$ & \\
\hline \multicolumn{3}{|c|}{ Final MBBS results category: } & & $<0.001^{\# \dagger}$ & & $<0.001^{\#+}$ \\
\hline \multicolumn{3}{|c|}{ First class } & $8.68 \pm 0.8$ & & $17.97 \pm 1.5$ & \\
\hline \multicolumn{3}{|c|}{ Second upper } & $7.91 \pm 1.3$ & & $17.24 \pm 1.8$ & \\
\hline \multicolumn{3}{|c|}{ Second lower } & $7.81 \pm 1.4$ & & $17.22 \pm 1.8$ & \\
\hline \multicolumn{3}{|c|}{ Pass } & $7.25 \pm 1.3$ & & $16.23 \pm 2.0$ & \\
\hline \multirow[t]{2}{*}{ Gender: } & Men & & $7.57 \pm 1.5$ & $0.095^{\# \#}$ & $17.04 \pm 1.9$ & $0.699^{\# \#}$ \\
\hline & Women & & $7.81 \pm 1.3$ & & $16.96 \pm 1.9$ & \\
\hline \multirow{2}{*}{\multicolumn{2}{|c|}{ Personal history of allergy: }} & Yes & $7.78 \pm 1.6$ & $0.584^{\# \#}$ & $17.27 \pm 2.0$ & $0.049^{\# \#}$ \\
\hline & & No & $7.70 \pm 1.3$ & & $16.85 \pm 1.9$ & \\
\hline \multirow{2}{*}{\multicolumn{2}{|c|}{ Family history of allergy: }} & Yes & $7.82 \pm 1.4$ & $0.323^{\# \#}$ & $17.15 \pm 1.9$ & $0.199^{\# \#}$ \\
\hline & & No & $7.67 \pm 1.4$ & & $16.89 \pm 1.9$ & \\
\hline
\end{tabular}

${ }^{\#} p$ value based on one-way ANOVA; ${ }^{\# \#} p$ value based on independent sample t test; ${ }^{\dagger} p$ value $<0.05$

history of allergy $(p=0.049)$ (Table 2). Post-hoc analysis with the Tukey test showed that there was a significant difference between first class vs pass without a class, second upper vs pass without a class and second lower vs pass without a class (all $p$ values $<0.05$ ). Post hoc analysis also showed that the management score significantly differed between University 1 and University 2 and between University 2 and University 3 (p values < 0.001 in both). On multiple linear regression analysis, being a graduate of University $2[\mathrm{~B}=1.568(95 \% \mathrm{CI}$

Table 3 Simple and multiple linear regression for case-diagnosis score with participant characteristics $(N=385)$

\begin{tabular}{|c|c|c|c|c|c|c|c|}
\hline \multirow[t]{2}{*}{ Model } & \multicolumn{2}{|c|}{ Unstandardized Coefficients } & \multirow{2}{*}{$\begin{array}{l}\text { Standardized Coefficients } \\
\text { Beta }\end{array}$} & \multirow[t]{2}{*}{$\mathbf{t}$} & \multirow[t]{2}{*}{ Sig. } & \multicolumn{2}{|c|}{$\begin{array}{l}95 \% \text { Confidence Interval } \\
\text { for B }\end{array}$} \\
\hline & $\mathrm{B}^{\mathrm{a}}$ & Std. Error & & & & Lower Bound & Upper Bound \\
\hline \multicolumn{8}{|l|}{ Simple linear regression } \\
\hline University 1 vs other universities & -0.211 & 0.147 & -0.073 & -1.434 & 0.152 & -0.500 & 0.078 \\
\hline University 3 vs other universities & 0.130 & 0.173 & 0.038 & 0.750 & 0.454 & -0.211 & 0.470 \\
\hline first class vs no first class & 1.012 & 0.321 & 0.159 & 3.157 & $0.002^{\dagger}$ & 0.382 & 1.642 \\
\hline class vs no class & 0.647 & 0.153 & 0.210 & 4.203 & $0.000^{+}$ & 0.342 & 0.944 \\
\hline Personal history of allergy & 0.083 & 0.151 & 0.028 & 0.548 & 0.584 & -0.214 & 0.380 \\
\hline Family history of allergy & 0.145 & 0.147 & 0.051 & 0.990 & 0.323 & -0.143 & 0.434 \\
\hline Gender & -0.244 & 0.146 & -0.085 & -1.673 & 0.095 & -0.532 & 0.043 \\
\hline \multicolumn{8}{|l|}{ Multiple linear regression } \\
\hline 1 (Constant) & 7.269 & .190 & & 38.290 & .000 & 6.896 & 7.642 \\
\hline University 1 vs other universities & -.179 & .156 & -.062 & -1.146 & .252 & -.486 & .128 \\
\hline University 3 vs other universities & .276 & .193 & .081 & 1.435 & .152 & -.102 & .655 \\
\hline first class vs no first class & .887 & .319 & .140 & 2.784 & $.006^{\dagger}$ & .261 & 1.514 \\
\hline class vs no class & .662 & .161 & .216 & 4.125 & $.000^{+}$ & .347 & .978 \\
\hline Personal history of allergy & .012 & .158 & .004 & .074 & .941 & -.300 & .323 \\
\hline Family history of allergy & .002 & .156 & .001 & .016 & .987 & -.304 & .309 \\
\hline Gender & -.185 & .146 & -.065 & -1.267 & .206 & -.473 & .102 \\
\hline
\end{tabular}

${ }^{a}$ Multiple Linear Regression used Enter Method; ${ }^{\dagger} p$ value $<0.05$ 
1.182-1.953), $p<0.001]$ and having a class at final MBBS [B $=0.716$ (95\% CI 0.319-1.113), $\mathrm{p}<0.001]$ were positive predictors of higher mean scores for the management of anaphylaxis (Table 4).

\section{Source of knowledge and skills}

$50.9 \%$ of respondents claimed that they knew about anaphylaxis before entering the university and 99 and $93.8 \%$ respectively agreed that they gained knowledge and skills related to anaphylaxis in their medical faculty. Overall, the most frequently reported source of knowledge during undergraduate years was teaching in the para clinical phase $(83.6 \%)$ and the most frequently reported source of skills were the final year clinical appointments (67.5\%). There were differences based on the university (Additional File 2 - Supplementary Table 3). A large proportion of graduates from Universities 2 and 3 reported that after qualifying with MBBS, they had attended workshops and seminars where they had gained knowledge and skills in the diagnosis and management of anaphylaxis.

\section{Self-confidence in diagnosing and managing anaphylaxis} Overall, 79.7\% were self-confident in diagnosing but only $62.1 \%$ were self-confident in managing anaphylaxis. The main reason given for lack of self-confidence in managing anaphylaxis was not having had sufficient handson experience. Significant differences in self-confidence levels were observed between universities (Table 5). There was a positive correlation between knowledge and perception scores and the presence of self-confidence (case-diagnosis score and self-confidence in diagnosis: $r_{\mathrm{pb}}=0.111, p=0.03$; score for management and selfconfidence in management of anaphylaxis: $r_{\mathrm{pb}}=0.164$, $p=0.001)$.

\section{Discussion}

A pre-intern medical graduate will have undergone 5 years of medical education, acquired their MBBS degree and is awaiting the one year of compulsory internship in a service setting prior to full registration as a medical practitioner. Subsequent to acquiring the MBBS degree, they have an interim few months until the internship starts. The participants for the study were drawn from this group of 'doctors'.

The principal findings of the study provide an overview of these pre-intern doctors' competence and areas for improvement in the diagnosis and management of anaphylaxis. Case scenarios were used to assess their knowledge and perceptions and their ability to identify non-anaphylactic allergic reactions. Less than 10\% could correctly differentiate between anaphylaxis and a simple allergic reaction in all instances. The inability to diagnose stemmed from two factors, a lack of awareness of different triggers and deficiency in knowledge on how to diagnose anaphylaxis based on criteria. Only $16 \%$ of

Table 4 Simple and multiple linear regression for score for management of anaphylaxis, with participant characteristics $(N=385)$

\begin{tabular}{|c|c|c|c|c|c|c|c|}
\hline \multirow[t]{2}{*}{ Model } & \multicolumn{2}{|c|}{ Unstandardized Coefficients } & \multirow{2}{*}{$\begin{array}{l}\text { Standardized Coefficients } \\
\text { Beta }\end{array}$} & \multirow[t]{2}{*}{$\mathbf{t}$} & \multirow[t]{2}{*}{ Sig. } & \multicolumn{2}{|c|}{$\begin{array}{l}95 \% \text { Confidence Interval } \\
\text { for B }\end{array}$} \\
\hline & $\mathrm{B}^{\mathrm{a}}$ & Std. Error & & & & Lower Bound & Upper Bound \\
\hline \multicolumn{8}{|l|}{ Simple linear regression } \\
\hline University 2 vs other universities & 1.755 & 0.176 & 0.455 & 9.992 & $0.000^{\dagger}$ & 1.410 & 2.100 \\
\hline University 3 vs other universities & -1.298 & 0.232 & -0.275 & -5.592 & $0.000^{\dagger}$ & -1.754 & -0.841 \\
\hline First class vs no first class & 1.041 & 0.449 & 0.118 & 2.319 & $0.021^{\dagger}$ & 0.158 & 1.924 \\
\hline Class vs no class & 1.117 & 0.210 & 0.262 & 5.310 & $0.000^{+}$ & 0.703 & 1.531 \\
\hline Personal history of allergy & 0.413 & 0.209 & 0.100 & 1.973 & $0.049^{\dagger}$ & 0.001 & 0.825 \\
\hline Family history of allergy & 0.263 & 0.204 & 0.066 & 1.288 & 0.199 & -0.139 & 0.665 \\
\hline Gender & 0.079 & 0.204 & 0.020 & 0.387 & 0.699 & -0.322 & 0.480 \\
\hline \multicolumn{8}{|l|}{ Multiple linear regression } \\
\hline 1 (Constant) & 15.729 & .233 & & 67.646 & .000 & 15.272 & 16.187 \\
\hline University 2 vs other universities & 1.568 & .196 & .406 & 7.987 & $.000^{+}$ & 1.182 & 1.953 \\
\hline University 3 vs other universities & -.167 & .248 & -.035 & -.673 & .501 & -.656 & .321 \\
\hline First class vs no first class & .736 & .401 & .083 & 1.838 & .067 & -.051 & 1.524 \\
\hline Class vs no class & .716 & .202 & .168 & 3.546 & $.000^{\dagger}$ & .319 & 1.113 \\
\hline Personal history of allergy & .025 & .199 & .006 & .126 & .900 & -.367 & .417 \\
\hline Family history of allergy & .115 & .196 & .029 & .587 & .557 & -.270 & .500 \\
\hline Gender & -.007 & .184 & -.002 & -.037 & .971 & -.368 & .355 \\
\hline
\end{tabular}

${ }^{\mathrm{a}}$ Multiple Linear Regression used Enter Method; ${ }^{\dagger} p$ value $<0.05$ 
Table 5 Self-confidence in diagnosis and management of anaphylaxis ( $N=385)$

\begin{tabular}{|c|c|c|c|c|c|}
\hline & $\begin{array}{l}\text { Overall } \\
(N=385)\end{array}$ & $\begin{array}{l}\text { University } 1 \\
(N=135)\end{array}$ & $\begin{array}{l}\text { University } 2 \\
(N=170)\end{array}$ & $\begin{array}{l}\text { University } 3 \\
(N=80)\end{array}$ & $\begin{array}{l}P \\
\text { value }^{\#}\end{array}$ \\
\hline I am confident in diagnosing anaphylaxis (\%) & 79.7 & 71.1 & 84.7 & 83.8 & $0.008^{+}$ \\
\hline I am confident in managing anaphylaxis (\%) & 62.1 & 52.6 & 75.9 & 48.8 & 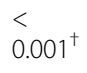 \\
\hline \multicolumn{6}{|c|}{ If you are not confident in managing anaphylaxis, what are your concerns? (\%) } \\
\hline $\begin{array}{l}\text { I have never seen emergency management of patients with } \\
\text { anaphylaxis }\end{array}$ & 5.4 & 5.2 & 7.0 & 2.4 & 0.329 \\
\hline $\begin{array}{l}\text { I have seen emergency management of patients withanaphylaxis but I } \\
\text { do not have hands-on experience }\end{array}$ & 32.5 & 42.2 & 17.1 & 48.8 & 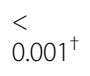 \\
\hline I am scared about the adverse effects of the drugs used & 0.5 & 1.5 & 0 & 0 & 0.155 \\
\hline
\end{tabular}

participants could correctly identify all the recognized environmental triggers. Surprisingly, major deficiencies in knowledge were about anaphylaxis triggers specifically encountered in the local setting such as chickpeas (Kadala), green gram (Mung), green leaves like spinach and Sarana (Boerhavia diffusa), coconut, banana and rice. It was notable that they were well aware of anaphylaxis triggers in the western world - this is probably the result of learning from western textbooks. $16 \%$ were unaware that anaphylaxis is diagnosed based on clinical criteria and 6\% were unaware that it can occur without skin manifestations. Precise and accurate knowledge about criteria for the diagnosis and their ability to apply them was deficient.

In terms of knowledge and skills in the acute management of anaphylaxis, 98\% were aware that adrenaline was the life-saving drug and that it should be given intramuscularly. Important deficiencies were noted about knowledge of adult and paediatric doses (21 and $44 \%$, respectively) and incorrect perceptions that if access is available adrenaline administration should be intravenous (10\%), that the best site of injection is the deltoid (22\%), that patients should be treated in semirecumbent position (25\%), that ischaemic heart disease, pregnancy, tachycardia and hypertension are contraindications for adrenaline (2-8\%) and that salbutamol nebulisation should be the first line of treatment if wheezing is the prominent symptom (13\%). In relation to long term management, not arranging follow up on discharge (50\%) and preventing affected persons from ever having any contact with any trigger identified as an allergen (27\%) were the key deficiencies noted.

There are eleven state medical faculties in Sri Lanka and the three chosen represented different medical curriculum approaches. The pre-interns' knowledge and skills in anaphylaxis had been acquired in different study years and in differing teaching and clinical settings. Despite these differences there was no difference in knowledge scores for diagnosis but one university (University 2) was ahead with regard to knowledge of management.
The one characteristic which defined higher knowledge about diagnosis and management was overall higher academic performance. As might be expected those who qualified in a higher degree category had higher competence in anaphylaxis diagnosis and treatment. In addition to knowledge, self confidence in management was assessed as it is required to bridge the gap between knowledge and practice. Even when knowledge scores were high, only $62 \%$ had the confidence to manage a patient with anaphylaxis. The main reason quoted for this less than ideal figure was a lack of hands-on experience.

The strengths and deficiencies of the methodology of the study determine the generalisability of the findings. Although there are 11 state medical faculties, graduates of only three were included. Despite them having different student intakes our research reached out to approximately a third of the total number of all national preinterns. As data collection was with an online questionnaire, a weakness of the study is that participants might have used external assistance to provide answers. Furthermore, although the face validity of the questionnaire was assessed further validation was not performed. The fact that the universities had different curricular models for student learning was not considered a limitation but was seen as an opportunity to assess whether any particular model of teaching was superior. Overall, our study reached $30 \%$ of all national pre-interns, had a high response rate exceeding $90 \%$ and the three chosen universities covered all the types of curricula adopted by all the medical faculties. These were strengths and support the national generalisability of the results.

In assessing how these findings compare with previous research from local and overseas settings, important differences emerge. In a previous Sri Lankan study with 98 practicing first contact doctors in the Gampaha district of Western province (the second most populous of the 25 districts in Sri Lanka), 96\% knew adrenaline to be the first line treatment, 77\% knew the correct route of administration, but only $31 \%$ were aware of the correct adult dose (19). Comparative figures for case scenario 
analysis (in the previous study there were a mix of five anaphylaxis and allergy case scenarios and in our study, there were 10), the success of doctors in previous study and pre-interns in this study were 2 and $7 \%$ respectively. These findings raise the possibility of attrition of knowledge and skills in the diagnosis and treatment of anaphylaxis over time. Similar studies from United Kingdom, United states, India, Turkey and New Zealand have reported that $45-94 \%$ had knowledge of adrenaline as the first line treatment, $9-78 \%$ knew that intramuscular route is the appropriate route and $15-33 \%$ knew the correct dose [13-18]. Comparative scores for the participants in present study were higher at 98,98 and $79 \%$, respectively. It should be noted that some of the studies outside Sri Lanka have been done in mixed populations of doctors, medical students, nurses and paramedics. A study from United Kingdom which included only doctors, ranging from consultants to junior doctors, reported that only $14.4 \%$ would administer adrenaline as recommended by the UK Resuscitation Council guidelines [13]. Knowledge was poor regardless of seniority or the specialty. A study from India reported that medical students performed better than interns [15]. Knowledge of diagnosis and treatment at levels similar to the present study have been reported in a study from Singapore amongst emergency department doctors. Here, $89 \%$ indicated adrenaline as the first line treatment, $85 \%$ chose intramuscular route and $73 \%$ knew the correct adult dose [19]. With regard to case scenarios, 89-94\% diagnosed the three case scenarios demonstrating anaphylaxis whereas in our study there were seven case scenarios of anaphylaxis and the correct diagnosis varied from 58 to $92 \%$. In addition, $43 \%$ of doctors incorrectly diagnosed single organ involvement without hypotension as anaphylaxis and in our study a comparable case scenario (Case 9) was diagnosed as anaphylaxis by $49 \%$. It appears that doctors in emergency departments, quite possibly due to continuous medical education and training, retain higher levels of knowledge. Long term management aspects were studied in Turkey and $85 \%$ suggested referring the patient to an allergy clinic (15). The comparative figure from our study was $50 \%$. In Sri Lanka there are only a few established specialised allergy clinics and this could be a reason for lack of awareness regarding follow up care.

There are several clinical and scientific implications of the findings of this study. When deficiencies in knowledge and self-confidence in the management of anaphylaxis exist, life-saving adrenaline may not reach patients at all or they may receive it in the wrong dose, resulting in severe adverse outcomes including death. Those with simple allergy, when mistakenly threated as having anaphylaxis, might also develop adverse effects unnecessarily.
The recommendation for medical educators is to formulate a structured educational programme, robust in knowledge of locally relevant anaphylaxis triggers, criteriabased diagnosis and appropriate management strategies to be implemented, along with an assessment certifying satisfactory competence. Considering that the pre-interns' knowledge and skills were superior to that of first contact doctors in a previous study, a recommendation to medical administrators and clinical supervisors is the requirement to organise anaphylaxis related continuing medical education and in-service training to prevent de-skilling.

The study highlighted the need for future research to develop and evaluate effective educational interventions to address the deficiencies detected. Such research could identify modes of effective enhancements at undergraduate and in-service programmes. Regular clinical auditing at institutional levels may identify the optimum frequencies for ongoing refresher programmes and quality improvement initiatives need to effectively assess ongoing competency status and take urgent actions to address deficiencies.

\section{Conclusions}

Knowledge, perceptions and self-confidence around the diagnosis and management of anaphylaxis was suboptimal among pre-intern medical graduates in Sri Lanka. Although suboptimal, these findings from preinterns were more favourable compared with findings from practicing doctors as in previous studies, probably because their knowledge was fresh. The study highlights the need to identify additional educational and training initiatives to narrow gaps in knowledge and practice to prepare and enhance the confidence and ability of newly graduated doctors for the provision of best care in this life-threatening emergency.

\section{Abbreviations}

ANOVA: Analysis of variance; FFP: Fresh Frozen Plasma; MBBS: Bachelor of Medicine, Bachelor of Surgery; NSAIDs: Non-Steroidal Anti-Inflammatory Drugs; SPSS: Statistical Package for the Social Sciences

\section{Supplementary Informations}

The online version contains supplementary material available at https://doi. org/10.1186/s12909-021-02588-w.

Additional file 1. Study Instrument. This is the questionnaire used for data collection.

Additional file 2: Supplementary Table 1, Supplementary Table 2 and Supplementary Table 3. Supplementary Table 1. Knowledge regarding triggers of anaphylaxis. Supplementary Table 2. Knowledge and perception regarding diagnosis and management of anaphylaxis. Supplementary Table 3.: Source of knowledge and skills related to diagnosis and management of anaphylaxis.

Acknowledgements

We thank Professor A Pali S Hungin for his contribution in editing the paper. We also thank Mr. Tharindu Wijekoon for his help in preparing the SPSS data set and all the study participants for their kind cooperation. 


\section{Authors' contributions}

CNW conceived and designed the study. IW, DF, AD, MG, GM and PT contributed to the conduct of the study and acquisition of data. CNW, IW, DF and AD contributed to data analysis and interpretation. CNW drafted the manuscript. All authors contributed to revise the manuscript critically and approved the final manuscript. All authors had full access to all of the data in the study and take responsibility for the integrity of the data and the accuracy of the data analysis.

\section{Funding}

This is a self-funded study.

\section{Availability of data and materials}

The datasets used and/or analysed during the current study are available from the corresponding author on reasonable request.

\section{Declarations}

\section{Ethics approval and consent to participate}

The Ethics Review Committee of the Faculty of Medical Sciences, University of Sri Jayewardenepura, Sri Lanka granted approval for this study [Ref. No.03/19].

All participants provided informed consent prior to participation in the study.

\section{Consent for publication}

Not applicable.

\section{Competing interests}

The authors declare that they have no competing interests.

\section{Author details}

'Department of Pharmacology, Faculty of Medical Sciences, University of Sri Jayewardenepura, Gangodawila, Nugegoda, Sri Lanka. ${ }^{2}$ Department of Physiology, Faculty of Medicine, University of Colombo, 25, Kynsey Road, Colombo 08, Sri Lanka. ${ }^{3}$ Department of Medicine, Faculty of Medicine, University of Ruhuna, PO Box 70, Galle, Sri Lanka.

\section{Received: 19 September 2020 Accepted: 26 February 2021}

\section{Published online: 09 March 2021}

\section{References}

1. Simons FER, Ardusso LRF, Bilò MB, et al. For the world allergy organization. World allergy organization guidelines for the assessment and Management of Anaphylaxis. World Allergy Organ J. 2011;4(2):13-37.

2. Simons FER, Ardusso LR, Bilò MB, et al. International consensus on (ICON) anaphylaxis. World Allergy Organ J. 2014;7(1):9.

3. Working Group of the Resuscitation Council (UK). Emergency treatment of anaphylactic reactions. Guidelines for healthcare providers. London: Resuscitation Council (UK); 2008. Available from https://www.resus.org.uk/a naphylaxis/emergency-treatment-of-anaphylactic-reactions/ (cited 28 August 2020)

4. Muraro A, Roberts $G$, Worm M, et al. On behalf of the EAACl food allergy and anaphylaxis guidelines group. Anaphylaxis: guidelines from the European academy of allergy and clinical immunology. Allergy. 2014;69: 1026-45.

5. Simons FE, Ebisawa M, Sanchez-Borges M, et al. 2015 update of the evidence base: world allergy organization anaphylaxis guidelines. World Allergy Organ J. 2015;8(1):32.

6. Simons FE. Anaphylaxis: recent advances in assessment and treatment. J Allergy Clin Immunol. 2009;124:625-36.

7. Sheikh A, Hippisley-Cox J, Newton J, Fenty J. Trends in national incidence, lifetime prevalence and adrenaline prescribing for anaphylaxis in England. J R Soc Med. 2008;101:139-43.

8. Wang Y, Allen KJ, Suaini NHA, McWilliam V, Peters RL, Koplin JJ. The global incidence and prevalence of anaphylaxis in children in the general population: a systematic review. Allergy. 2019;74:1063-80.

9. Panesar SS, Javad S, de Silva D, Nwaru BI, Hickstein L, Muraro A, et al. The epidemiology of anaphylaxis in Europe: a systematic review. Allergy. 2013; 68:1353-61.

10. Grabenhenrich L, Hompes S, Gough H, Rueff F, Scherer K, et al. Implementation of anaphylaxis management guidelines: a register-based study. PLoS One. 2012;7(5):e35778.
11. Khan NU, Shakeel N, Makda A, Mallick AS, Ali Memon M, SHW H, et al. Anaphylaxis: incidence, presentation, causes and outcome in patients in a tertiary-care hospital in Karachi, Pakistan. Q J Med. 2013;106:1095-101.

12. Droste J, Narayan N. Anaphylaxis: lack of hospital doctors' knowledge of adrenaline (epinephrine) administration in adults could endanger patients' safety. Eur Ann Allergy Clin Immunol. 2012;44:122-7.

13. Grossman SL, Baumann BM, Garcia Peña BM, Linares MYR, Greenberg B, Hernandez-Trujillo VP. Anaphylaxis knowledge and practice preferences of pediatric emergency medicine physicians: a national survey. J Pediatr. 2013; 163(3):841-6.

14. Drupad $\mathrm{H}$, Nagabushan $\mathrm{H}$. Level of knowledge about anaphylaxis and its management among health care providers. Indian J Crit Care Med. 2015; 19(7):412.

15. Baççioğlu A, Uçar EY. Level of knowledge about anaphylaxis among health care providers. Tuberk Toraks Tuberkuloz Ve Toraks. 2013;61(2):140-6.

16. Erkoçoğlu M, Civelek E, Azkur D, et al. Knowledge and attitudes of primary care physicians regarding food allergy and anaphylaxis in Turkey. Allergol Immunopathol. 2013;41(5):292-7.

17. Thain S, Rubython J. Treatment of anaphylaxis in adults: results of a survey of doctors at Dunedin hospital, New Zealand. NZ Med J. 2007:120(1252):1-8.

18. Ibrahim I, Chew BL, Zaw W, et al. Knowledge of anaphylaxis among emergency department staff. Asia Pac Allerg. 2014;4(3):164.

19. Fernando D, Attapattu PM, Weerasinghe SDSMP, Dayaratne TT. Anaphylaxis: are doctors adequately aware? A study on perceptions and practices among first-contact-level doctors in state healthcare institutions in Gampaha district. Journal of the Ceylon College of Physicians. 2016;47:86-91.

\section{Publisher's Note}

Springer Nature remains neutral with regard to jurisdictional claims in published maps and institutional affiliations.

Ready to submit your research? Choose BMC and benefit from:

- fast, convenient online submission

- thorough peer review by experienced researchers in your field

- rapid publication on acceptance

- support for research data, including large and complex data types

- gold Open Access which fosters wider collaboration and increased citations

- maximum visibility for your research: over $100 \mathrm{M}$ website views per year

At $\mathrm{BMC}$, research is always in progress.

Learn more biomedcentral.com/submission 